\title{
Critical Evaluation of Experimental Data of Solution Enthalpy of Zirconium in Liquid Aluminum
}

\author{
M. Barrachin, K. Gajavalli, A. Decreton, F. Virot \\ Institut de Radioprotection et de Sûreté Nucléaire PSN-RES, SAG, LETR, Saint Paul les Durance cedex \\ 13115, France \\ P. Bénigni, J. Rogez, G. Mikaelian \\ Université Aix-Marseille, IM2NP, UMR7334, CNRS, Campus de Saint Jérôme, Avenue Escadrille \\ Normandie Niémen-Case 251, 13397 Marseille cedex 20, France \\ E. Fischer \\ Université Grenoble Alpes, CMTC, SIMAP, 38000 Grenoble, France \\ M. Lomello-Tafin, C. Antion, A. Janghorban \\ Laboratoire SYMME, Polytech Annecy Chambéry-Université de Savoie, BP. 80439, 74944 Annecy-Le-Vieux \\ Cedex, France
}

\begin{abstract}
The aim of the present paper is to propose a new interpretation of the zirconium dissolution in liquid aluminum calorimetry experiments performed in the past in order to reconcile some apparently contradictory results and observations. It is supported by the development of a dissolution kinetics model. We show that probably most of the experiments interpreted in terms of dissolution must be considered in terms of (partial or total) transformation of zirconium into zirconium aluminide $\left(\mathrm{Al}_{3} \mathrm{Zr}\right)$. In addition, on the basis of the developed model, we propose some recommendations in terms of experimental conditions to improve the dissolution process. These recommendations are consistent with some empirical rules derived in the past. It also puts in question past standard enthalpy measurements of some compounds in the $\mathrm{Cu}-\mathrm{Zr}, \mathrm{Ni}-\mathrm{Zr}, \mathrm{Co}-\mathrm{Zr}$ and $\mathrm{U}-\mathrm{Zr}$ systems.
\end{abstract}

\section{Introduction}

In high temperature solution calorimetry, the standard enthalpy of formation of a compound $\mathrm{A}_{\alpha} \mathrm{B}_{\beta}$, is determined from the separate experimental determinations of the solution enthalpies of the compound $\left(\mathrm{A}_{\alpha} \mathrm{B}_{\beta}\right)$ and its components $\mathrm{A}$ and $\mathrm{B}$ in a same solvent bath at the same temperature, according to the equation :

$$
\Delta_{f} H^{0}\left(A_{\alpha} B_{\beta}\right)=\alpha \Delta_{s o l} H^{\infty}(A)+\beta \Delta_{\text {sol }} H^{\infty}(B)-\Delta_{\text {sol }} H^{\infty}\left(A_{\alpha} B_{\beta}\right)
$$


where :

- $\alpha$ and $\beta$ are the stoichiometric coefficients of the $\mathrm{A}_{\alpha} \mathrm{B}_{\beta}$ compound,

- $\Delta_{f} H^{0}\left(A_{\alpha} B_{\beta}\right)$, the standard enthalpy of formation of the $\mathrm{A}_{\alpha} \mathrm{B}_{\beta}$ compound,

- $\Delta_{\text {sol }} H^{\infty}(X)$, the solution enthalpy of $X=A\left(\right.$ or $B$ or $\left.A_{\alpha} B_{\beta}\right)$ at infinite dilution in the solvent.

The solution enthalpy of $X$ is determined by successive drops of $X$ (initially at the standard temperature, $298.15 \mathrm{~K}$ ) in the solvent and by measuring the associated heat effects which are, once divided by the number of added moles of $X$, extrapolated at infinite dilution in order to obtain $\Delta_{\text {sol }} H^{\infty}(X)$.

For most transition metals and in particular for Group IV elements such as titanium, hafnium or zirconium, the choice of the solvent is a crucial problem since their dissolution in many ones classically used in high temperature calorimetry is a slow process. Such slow kinetics requires to guarantee the thermal stability of the calorimeter over large times and this is a difficult task at high temperature. However some refractory transition elements were successfully dissolved in metallic solvents, Ti and Hf in liquid tin [1] or in liquid germanium [2]. For zirconium, Yassin et al. [1] reported two very different values for solution enthalpies in liquid tin at infinite dilution from Sudavtsova et al. [3] and from Bouhajib et al. [4] whereas in liquid germanium, no data was available up to now. Preliminary experiments of zirconium dissolution in liquid germanium at $1273 \mathrm{~K}$ were performed in our laboratory to check the possibility of using this solvent. The measured solution enthalpies showed a large dispersion $( \pm 20$ $\left.\mathrm{kJ} . \mathrm{mol}^{-1}\right)$. Moreover there was apparently a non-linear variation of solution enthalpies with zirconium concentration, preventing any reliable extrapolation at infinite dilution.

Molten aluminum was also extensively used by different groups as reported in a review by Colinet [5]. Numerous experimental determinations of solution enthalpies of zirconium in liquid aluminum were performed at temperatures around $\approx 1000 \mathrm{~K}$ [6-14] and at higher temperatures, above $1673 \mathrm{~K}$ up to $2045 \mathrm{~K}$ [15-19]. In the framework of a recent study of the Ag-Zr phase diagram [20] devoted to the determination of the standard enthalpies of formation of $\mathrm{AgZr}$ and $\mathrm{AgZr}_{2}$ compounds, new values of zirconium solution enthalpy in liquid aluminum at $996 \mathrm{~K}$ have been obtained by our group. The comparison between our value and the previous ones highlights a rather good agreement (Table 1) even if one can consider the values somewhat dispersed. Regarding these results, to use liquid aluminum for zirconium dissolution at temperatures around $\approx 1000 \mathrm{~K}$ seemed to be a promising way.

Colinet [5] mentioned that attemps to dissolve zirconium in liquid aluminum at temperatures around $1000 \mathrm{~K}$ usually failed, but without giving any explanation. In fact, the reason is linked to the formation of the intermetallic compound $\left(\mathrm{Al}_{3} \mathrm{Zr}\right)$ at the liquid/metal interface in the very beginning of the dissolution process. Once a thin layer of zirconium aluminide forms by chemical reaction between zirconium and aluminum, the direct contact between the sample core and liquid is prevented. The kinetics of incorporation of zirconium atoms in the bath is then controlled by the competition between the dissolution of the outer layer of $\mathrm{Al}_{3} \mathrm{Zr}$ by the liquid phase and the growth of this intermetallic layer towards the sample core. Solid-state diffusion experiments 
between 826 and $913 \mathrm{~K}$ by Kidson et al. [21] showed that the diffusion of aluminum in $\mathrm{Al}_{3} \mathrm{Zr}$ was much higher than the one of zirconium. It was explained in [21] by the similarity of the $\mathrm{Al}(\mathrm{fcc})$ and $\mathrm{Al}_{3} \mathrm{Zr}\left(\mathrm{DO}_{23}\right)$ structures where the interatomic distances between aluminum atoms is $2.86 \AA$ in the first one, whereas it is $2.80 \AA$ and $2.85 \AA$ in the second one. It leads to a rapid growth of a $\mathrm{Al}_{3} \mathrm{Zr}$ layer (to the apparent exclusion of all other $\mathrm{Al}-\mathrm{Zr}$ intermetallic compounds) which acts as a barrier for zirconium atoms. In the dissolution calorimetry experiments, such a phenomenon could lead to a complete transformation of the zirconium solid sample into aluminide before its sluggish dissolution.

In the $\mathrm{Al}-\mathrm{Zr}$ phase diagram, at $\approx 1000 \mathrm{~K}$, the limit of the (Liquid $+\mathrm{Al}_{3} \mathrm{Zr}$ ) biphasic domain is reached for a zirconium atomic fraction of 0.0008 , according to the recent experimental data of Dezellus et al. [22]. Almost all the groups (Table 1) investigated a range of zirconium atomic fractions exceeding the zirconium solubility in liquid aluminum. They surprisingly did not mention any composition dependence of the solution enthalpy of zirconium in liquid aluminum. In our experiments [20], the measured heat flows effectively showed slight or no difference below and above the solubility whereas different thermal effects are expected corresponding to a dissolution process below the solubility and a precipitation of a solid phase (i.e. $\mathrm{Al}_{3} \mathrm{Zr}$ ) above the solubility. From these observations, it can be assumed that the transformation that occurs in the calorimeter below and above the solubility could correspond to the same chemical process, i.e. :

$$
<Z r>_{298.15 K}+3((A l))_{T} \rightarrow<A l_{3} Z r>_{T}
$$

Whereas they obtained a similar value that ours, Gomozov et al. $[10,11]$, claimed that the examination of their bath after the experiments showed an uniform distribution of zirconium in aluminum without aluminide precipitation. On the contrary Eremenko et al. [23] previously showed that, for dissolution tests of a zirconium disc specimen immersed in liquid aluminum at $973 \mathrm{~K}$, zirconium was completely transformed into $\mathrm{Al}_{3} \mathrm{Zr}$.

The occurence of Reaction (2) likely depends on the experimental conditions. On the basis of experimental observations on different chemical metallic aluminum-based systems, Eremenko et al. [24] derived some empirical rules required to prevent the growth of the aluminide layer, i.e. a bath temperature above $1050 \mathrm{~K}$, a sample area-tovolume ratio of $10 \mathrm{~m}^{-1}$ and a concentration of dissolved metal below 0.4-0.6 times the solubility limit at the bath temperature.

The aim of the present paper is to propose a new interpretation of the zirconium dissolution in liquid aluminum calorimetry experiments performed in the past in order to reconcile some apparently contradictory results and observations. It is supported by the development of a dissolution kinetics model described in Section 3. As the thermal signal of the calorimeter is continuously recorded during the dissolution process, the return of the signal to the baseline after each zirconium drop provides an estimate of the duration of this process. The model predictions allow to evaluate the reliability of the published values of enthalpy of solution zirconium in aluminum bath around $1000 \mathrm{~K}$. 


\section{Experimental observations in our tests}

The experimental procedure and conditions of our tests are detailed in [20]. Some information are summarised here. The measurements were performed under argon gas at a pressure slightly over $1 \mathrm{bar}$ in a Tian-Calvet high temperature calorimeter. The temperatures of the reference and the sample cells were measured by a Pt10\% Rh-Pt thermocouple inserted between the cells in the isothermal alumina block. $9.1 \mathrm{~g}$ of aluminum was put in a graphite crucible. The crucible was inserted in a vitreous silica tube. As the silica tube was slowly lowered into the calorimeter maintained at the experiment temperature, the metallic load melted and after a transient thermal regime, the whole assembly reached thermal equilibrium and a stable baseline was obtained. Small fragments of zirconium about few $\mathrm{mg}$ were then dropped successively until a target final composition was reached. Masses were weighed on a balance of $\pm 10^{-5} \mathrm{~g}$ accuracy. The differential signal of the calorimeter was continuously recorded during the process. After each drop, a thermal effect was registered before the signal has returned to the baseline.

The duration of the dissolution process can be estimated as the time interval between the sample drop and the return to the baseline. This return can be in some cases difficult to assess. It is considered that our measurements of thermal effects are accurate within $\pm 5 \%$. According to the fact that the thermal effect is proportional to the sample mass, approximately $95 \%$ of the sample is dissolved during the dissolution process duration. After the final zirconium addition, the atomic fraction of $\mathrm{Zr}$ in the bath was about 0.000667 (i.e. about $89 \%$ of the solubility limit at $996 \mathrm{~K}$, i.e. 0.00075 [22]). The silica tube assembly containing the sample was then extracted from the calorimeter and the sample cooled down to room temperature under inert atmosphere for further analyses which are discussed in Part 4.

\section{Description of the model}

\subsection{Introduction}

As explained in detail by Yatsenko et al. [25], when there is no formation of intermetallic layer, the dissolution of zirconium in liquid aluminum consists in breakdown of metallic bonds holding atoms on the surface of solid zirconium and their replacement by bonds between atoms in the liquid phase. The second stage is the removal of the reaction products from the solid/liquid interface into the bulk of the liquid aluminum bath. Diffusion through the solid/liquid boundary layer often acts as a limiting process. The dissolution rate in this case is directly proportional to the zirconium concentration difference between the solid/liquid interface and the bulk of the liquid. According to this description, the dissolution process of solid in liquid aluminum can be described by the Nernst-Shchukarev equation (commonly used, see e.g. [23], [25]) :

$$
\frac{d C(t)}{d t}=K \frac{S}{V}\left[C_{s}-C(t)\right]
$$

where $C(t)$ is the concentration of the dissolved metal in the liquid bulk at time $t, C_{s}$, the metal concentration in the liquid at saturation (as given by the Al-Zr phase diagram), 
$t(s)$ the dissolution time, $S\left(\mathrm{~m}^{2}\right)$ the sample surface area, $V\left(\mathrm{~m}^{3}\right)$ the melt volume, and $K\left(m \cdot s^{-1}\right)$, the mass transfer coefficient.

With this equation, it is assumed that there is no concentration gradient in the liquid bulk. $K$ takes into account the diffusion and convection mass transfer in the boundary layer. To solve the previous equation, the key point is the determination of $K$. This is the aim of the next section.

\subsection{Determination of the mass transfer coefficient around a sphere}

In our calorimetric experiments, we assume that the zirconium sample to be dissolved can be considered as a sphere in isothermal conditions. The spherical geometry is kept during the dissolution process but the dimensions of the sphere are continuously reduced as a function of the dissolved mass.

For heat transfer with natural convection around a sphere of diameter $d$, Bejan [26] recommends to use the Churchill's relation [27] between the Nusselt $(\mathrm{Nu})$, the Prandtl $(P r)$ and the Rayleigh $(R a)$ dimensionless numbers (with the validity ranges $\operatorname{Pr} \geq 0.7$ and $\left.R a_{d} \leq 10^{11}\right)$ :

$$
N u_{d}=2+\frac{0.589 R a_{d}^{1 / 4}}{\left[1+(0.469 / P r)^{9 / 16}\right]^{4 / 9}}
$$

The mass transfer coefficient $K$ of Equation (3) is then estimated using the classical analogy between heat and mass transfers. For mass transfer with natural convection around a sphere, we then use the following expression linking the Grashof $\left(G r_{m}\right)$, the Sherwood $(S h)$ and the Schmidt $(S c)$ dimensionless numbers :

$$
S h=2+\frac{0.589 G r_{m}^{1 / 4} S c^{1 / 4}}{\left[1+(0.469 / S c)^{9 / 16}\right]^{4 / 9}}
$$

where $G r_{m}, S c$ and $S h$ are given by :

$$
\left\{\begin{aligned}
G r_{m} & =g \frac{\Delta \rho}{\rho_{l}} \frac{d^{3}}{v^{2}} \\
S c & =\frac{v}{D_{0}} \\
S h & =\frac{K d}{D_{0}}
\end{aligned}\right.
$$

where $g\left(m \cdot s^{-2}\right)$ is acceleration due to gravity, $d(m)$ the diameter of the sphere, $\rho_{l}\left(\mathrm{~kg} \cdot \mathrm{m}^{-3}\right)$ the liquid density, $v\left(\mathrm{~m}^{2} \cdot \mathrm{s}^{-1}\right)$, the kinematic viscosity, $D_{0}\left(\mathrm{~m}^{2} \cdot \mathrm{s}^{-1}\right)$ the diffusion coefficient of solute in liquid, $\Delta \rho=\rho_{l s}-\rho_{l}$, the difference of density between the liquid at saturation and the bulk liquid. If $\Delta \rho=0$, Equation (5) is reduced to $S h=2$ which provides the limiting value of the Sherwood number for mass transfer from a sphere in a fluid in absence of convection.

Assuming a zero excess volume between $\mathrm{Al}$ and $\mathrm{Zr}$ in liquid for the calculation 
of the density of liquid phase ${ }^{1}$

$$
\frac{\Delta \rho}{\rho_{l}}=\frac{\rho_{l s}-\rho_{l}}{\rho_{l}} \approx \frac{\left(\rho_{l, A l}-\rho_{l, Z r}\right)\left(C-C_{s}\right)}{\rho_{l, A l} C_{s}+\rho_{l, Z r}\left(1-C_{s}\right)}=A_{1}\left(C_{s}-C\right)
$$

with :

$$
A_{1}=\frac{\rho_{l, Z r}-\rho_{l, A l}}{\rho_{l, A l} C_{s}+\rho_{l, Z r}\left(1-C_{s}\right)}
$$

The expression for $K$ becomes :

$$
K=B_{0}+\frac{B_{1}\left(C_{s}-C\right)^{1 / 4}}{B_{2}}
$$

with :

$$
\left\{\begin{array}{l}
B_{0}=\frac{2 D_{0}}{d} \\
B_{1}=0.589 \frac{D_{0}}{d}\left(\frac{A_{1} g d^{3}}{D_{0} v}\right)^{1 / 4} \\
B_{2}=\left[1+\left(0.469 D_{0} / v\right)^{9 / 16}\right]^{4 / 9}
\end{array}\right.
$$

Equation (3) of the evolution of the zirconium concentration in the liquid becomes :

$$
\frac{d C(t)}{d t}=\frac{S}{V} B_{0}\left[C_{s}-C(t)\right]+\frac{S}{V} \frac{B_{1}}{B_{2}}\left[C_{s}-C(t)\right]^{5 / 4}
$$

As previously mentioned, to establish Equation (11), samples of spherical shape are assumed. The previous expression can be derived similarly for any shape of sample if a $\mathrm{Nu}-\mathrm{Ra}$ relation has been determined. For immersed body of "not simple" volumes, Bejan [26] recommends to use the Yovanovich's relation [32] (with the validity ranges $S c \geq 0.7$ and $R a_{l} \leq 10^{8}$ ) for heat transfer. This relation becomes for mass transfer :

$$
S h_{l}=3.47+0.51 G r_{m}^{1 / 4} S c_{m}^{1 / 4}
$$

where $l$, is the square root of the entire area, $S$, of the immersed body.

In Equations (10), $d$ is simply replaced by an equivalent length equal to $S^{1 / 2}$. Equation (11) has then to be solved for :

\footnotetext{
${ }^{1}$ As the authors are aware, there is no density measurements of Al-Zr liquids around $1000 \mathrm{~K}$. In liquid aluminum binary alloys, it is reported in [28-30], from measurements on different Al-M binary systems $(\mathrm{M}=\mathrm{Ni}, \mathrm{Cr}, \mathrm{Co}, \mathrm{Fe}, \mathrm{Ti}, \ldots)$, that the molar volume of liquid alloy of composition $\left(\mathrm{x}_{A l}, \mathrm{x}_{M}\right)$ at temperature $T$ can be fitted, from the molar volumes of pure elements, $V_{A l}(T)$ and $V_{M}(T)$ at $T$, by a Redlich-Kister polynom [31] :

$$
V(T)=x_{A l} V_{A l}(T)+x_{M} V_{M}(T)+x_{A l} x_{M} \sum_{v=0}{ }^{v} V(T)\left(x_{A l}-x_{M}\right)^{v}
$$

In very dilute solutions (in our case, $x_{Z r}$ does not exceed 0.0008 ), we can reasonably assume that the excess volume can be neglected.
} 


$$
\left\{\begin{array}{l}
B_{0}=\frac{3 \cdot 47 D_{0}}{S^{1 / 2}} \\
B_{1}=0.51 \frac{D_{0}}{S^{1 / 2}}\left(\frac{A_{1} g S^{3 / 2}}{D_{0} v}\right)^{1 / 4} \\
B_{2}=1
\end{array}\right.
$$

\subsection{Concentration evolution equation}

Equation (11) is a differential equation of Bernoulli-type [33] with an exact known solution :

$$
\frac{d y(t)}{d t}+a y(t)=b y^{m}(t)
$$

with $y(t)=C_{s}-C(t), a=S B_{0} / V, b=-S B_{1} /\left(V B_{2}\right)$ et $m=5 / 4$.

As $a$ and $b$ vary with time because of the geometric modifications of the sample $(S)$ and the bath (increase of $V$ ) due to dissolution, we have to numerically integrate Equation (14) step by step.

Between $t=n \delta t$ et $t=(n+1) \delta t$, the solution of Equation (11) can be written under the general following form [33] :

$$
C(t)=C_{s}-\left[C_{s}-C\left(t_{n}\right)\right] e^{-a_{n}\left(t-t_{n}\right)}\left[1-C_{s}^{0.25} \frac{b_{n}}{a_{n}}+C_{s}^{0.25} \frac{b_{n}}{a_{n}} e^{-0.25 a_{n}\left(t-t_{n}\right)}\right]^{-4}
$$

where $a_{n}$ and $b_{n}$ are the values of $a$ and $b$ (respectively) calculated at the beginning of the time step, $t=n \delta t$, and assumed to be constant during $\delta t$.

\subsection{Numerical implementation of the model}

We have reported in Table 2 the parameter values required to re-interpret the past dissolution experiments with our model. The experiments performed by Ansara et $a l$. [6], Nagarajan et al. [7], and by Turchanin et al. [12, 14] are unfortunately not enough documented to be taken into account in this work.

For Turchanin et al. [8, 9, 13] and Gomozov et al. [10, 11], the sample geometries are not specified. For both studies, the initial $S / V$ ratios provide estimates of the initial sample areas, $S$, from the bath volume. According to Equations (11) and (13), the dissolution rate is an increasing function of $S$. By keeping during the calculation, the sample area, $S$, constant, equal to its initial value, the rate of concentration variation, $d C(t) / d t$, is maximised. Within this approximation, the calculation will provide a lower bound for the dissolution time for the tests for which the sample geometry is not known.

The viscosity and the density of liquid aluminum are taken from the Assael's assessment [34]. They are assumed to be constant during the dissolution process, according to the fact that small zirconium additions do not drastically modify the bath properties. The density of solid zirconium is taken from Lu et al.[35]. The density of liquid zirconium is equal to $6210 \mathrm{~kg} \cdot \mathrm{m}^{-3}$ at the zirconium melting temperature as recently determined by Ishikawa et al. [36]. The diffusion coefficient of zirconium in 
liquid aluminum was determined by Eremenko et $a l$. [37]. For the zirconium solubility in liquid aluminum, around $1000 \mathrm{~K}$, the different available experimental values from Fink et al. [38], Chiotti et al. [39], Eremenko et al. [23] and Yatsenko et al. [25] are in agreement and have been recently confirmed by Dezellus et $a l$. [22].

Some numerical tests have been performed to test the time-step convergence for the integration of Equations (11). Retained time-step of $1 s$ is accurate enough to obtain the convergence.

\section{Discussion}

\subsection{Our experiments at $996 \mathrm{~K}$}

\subsubsection{Simulation of the dissolution process}

According to our experimental conditions at $996 \mathrm{~K}$, we have simulated (Figure 1) the dissolution of the first sample dropped ( $3.5 \mathrm{mg}$ ), assumed to be spherical, in the aluminum bath $(9.1 \mathrm{~g})$. The calculation shows that the sample should be dissolved in $\approx 6$ hours. It is much longer than the duration of the thermal effect (less than one hour) measured in our calorimetry experiments. The dissolution kinetics is not largely modified by taking into account the Yovanovich's correlation (Figure 1).

In our calculation, a questionable approximation is to consider our sample as spherical. According to the isoperimetric inequality [40], for a given mass (so for a given volume), such a geometry leads to minimise the surface of the sample and then to increase the dissolution time, according to Equations (11) and (13). As our sample is not perfectly spherical, the calculated dissolution time is probably overestimated. Nevertheless, if we would like to obtain a calculated dissolution time comparable to the experimental one, a $S / V \approx 5-10 \mathrm{~m}^{-1}$ should be considered. Such a ratio would correspond to a very thin zirconium sheet clearly not representative of the geometry of our samples. So the calculated duration for the dissolution process gives an order of magnitude which is not compatible with the observation.

During the main part of the dissolution process, the Sherwood number (Figure 2) is largely higher than 2 , this value corresponding to the diffusive limit. It demonstrates that kinetics of dissolution which takes place at the solid-liquid interface is mainly governed by natural convection driven by the density difference between zirconium and aluminum in the melt.

\subsubsection{Interpretation of the measured thermal effect}

The numerical simulation puts in evidence that the measured thermal effect in our calorimetric experiments at $996 \mathrm{~K}$ does not correspond to a dissolution process. According to our interpretation, the heat measured in the calorimetric experiments should correspond to the enthalpy of formation of $\mathrm{Al}_{3} \mathrm{Zr}$ from solid zirconium at $298.15 \mathrm{~K}$ and liquid aluminum at the bath temperature, $T=996 \mathrm{~K}$ (reaction 2). Then we assume that, once the aluminide formed in the calorimeter, it is not dissolved in the aluminum bath. In this framework, the heat involved in the aluminide formation can be estimated from the heats involved in the following reactions : 


$$
\left\{\begin{array}{cc}
<Z r>_{298.15 K}+3((A l))_{T} \rightarrow<A l_{3} Z r>_{T} & \Delta H_{2}(T) \\
<Z r>_{298.15 K}+3<A l>_{298.15 K} \rightarrow<A l_{3} Z r>_{298.15 K} & \Delta_{f} H^{A l_{3} Z r}(298.15 K) \\
<A l_{3} Z r>_{298.15} \rightarrow<A l_{3} Z r>_{T} & \Delta H^{A l_{3} Z r}(T) \\
<A l>_{298.15 K} \rightarrow((A l))_{T} & \Delta H^{A l}(T)
\end{array}\right.
$$

The heat involved in Reaction (2) can be written :

$$
\Delta H_{2}(T)=-3 \Delta H^{A l}(T)+\Delta_{f} H^{A l_{3} Z r}(298.15 K)+\Delta H^{A l_{3} Z r}(T)
$$

Considering a propagation law of the uncertainties, an uncertainty on $\Delta \mathrm{H}_{2}$ can be estimated by the square root of the sum of squares of the different terms of (17) [41] :

$$
\delta\left[\Delta H_{2}(T)\right]=\sqrt{9 \delta_{\Delta H^{A l}(T)}^{2}+\delta_{\Delta_{f} H^{A l} z_{r}(298.15 K)}^{2}+\delta_{\Delta H^{A l_{3} Z r}(T)}^{2}}
$$

The uncertainty on pure $\mathrm{Al}$ heat content is much lower than the uncertainty on $\Delta_{f} H^{A l_{3} Z r}(298.15)$, so the previous equation is reduced to :

$$
\delta\left[\Delta H_{2}(T)\right] \approx \sqrt{\delta_{\Delta_{f} H^{A l} l_{3} z r(298.15 K)}^{2}+\delta_{\Delta H^{A l} Z z_{(T)}}^{2}}
$$

To calculate $\Delta H_{2}(T)$, different values, reported in Table 3, can be considered for the standard enthalpy of formation of $\mathrm{Al}_{3} \mathrm{Zr}, \Delta_{f} H^{\mathrm{Al}_{3} \mathrm{Zr}}(298.15 \mathrm{~K})$, and for its enthalpic increment.

For $\Delta_{f} H^{A l_{3} Z r}(298.15 K)$, the first value determined by dissolution calorimetry was reported by Alcock et al. [42] who mentioned that the aluminide sample was not quite homogeneous. Kematick et al. [43] determined $\Delta_{f} H^{\mathrm{Al}_{3} Z r}(298.15 \mathrm{~K})$ by measuring the $\mathrm{Al}$ vapour pressure over the different aluminides of the $\mathrm{Al}-\mathrm{Zr}$ system from pure $\mathrm{Zr}$ to 75 at. $\% \mathrm{Al}$ in the temperature interval $1298-1673 \mathrm{~K}$ by means of Knudsen cell mass spectrometry. Using the Neumann-Kopp rule and assuming the absence of composition ranges for the aluminides, they derived the standard enthalpy values for the different alloys by means of the second- and third-law methods. Since they did not consider the difference between the Gibbs energies of liquid and solid $\mathrm{Al}$ above the $\mathrm{Al}$ melting temperature, Murray et $a l$. [44] corrected these data with $-196 \pm 4 \mathrm{~kJ} . \mathrm{mol}^{-1}$. Esin et $a l$. [45] measured by adiabatic calorimetry, the heat increments of $\mathrm{Al}_{3} \mathrm{Zr}$ in the temperature range $298-2000 \mathrm{~K}$ from monophasic samples previously controlled by metallography and X-ray analyses. Using an Hess's cycle, experimental data for the enthalpy of formation of liquid $\mathrm{Al}_{3} \mathrm{Zr}$ at $1970 \mathrm{~K}$ [18], and heat increments for $\mathrm{Al}$ and $\mathrm{Zr}$ [46], they gave $-170.4 \mathrm{~kJ} \cdot \mathrm{mol}^{-1}$ for the standard enthalpy of formation of $\mathrm{Al}_{3} \mathrm{Zr}$. Applying the same methodology with the data of Witusiewicz al. [19], we obtained $-193.5 \mathrm{~kJ}^{-\mathrm{mol}^{-1}}$. Meschel et al. [47] used direct calorimetry at $1473 \mathrm{~K}$ and confirmed by X-ray the crystallographic structure of the formed aluminide as well as the absence of unreacted 
metals. In a second step, they recovered the aluminide sample from the boron nitride crucible to measure the heat increment from room temperature to $1473 \mathrm{~K}$ for which they obtained a value in agreement with the data of Esin et al. [45, 48]. Finally they reported for $\Delta_{f} H^{A l_{3} Z r}(298.15 K),-193.6 \pm 5.2 \mathrm{~kJ} \cdot \mathrm{mol}^{-1}$, supporting the Murray's assessed value. More recently, very different $\Delta_{f} H^{A l_{3} Z r}(298.15 K)$ values obtained by using a technique coupling thick multilayer foils and differential scanning calorimetry were reported by Weihs et al. [49] and Fischer et al. [50]. Finally, different assessments of the Al-Zr phase diagrams have been published [44, 51-53], in particular the two most recent and complete ones, from Wang et al. [52], Fischer et al. [53], and Tamim et al. [54], reflecting the absence of consensus on the $\Delta_{f} H^{A l_{3} Z r}(298.15 K)$ value. Wang et $a l$. selected the value of $-194.2 \mathrm{~kJ} \mathrm{~mol}^{-1}$ in agreement with the experimental data of Meschel et $a l$. [47], whereas Fischer et $a l$. preferred to consider a value in a consistent set of ab-initio calculated enthalpies of formation at $0 \mathrm{~K}$ for the different compounds in the Al-Zr system.

With the Quantum Espresso code [55], we have performed DFT simulations within the GGA-PBE approximation to calculate $\Delta_{f} H^{A l_{3} Z r}(0 K)$ for the stable $\mathrm{D}_{23}$ structure of $\mathrm{Al}_{3} \mathrm{Zr}$, the zero-point energies, and the enthalpic terms described within the framework of the harmonic approximation, in order to evaluate the order of magnitude of the vibrational contributions. Theoretically, the enthalpy of formation at $0 \mathrm{~K}$ resulting from an ab initio calculation corresponds to only electronic contributions. It should be corrected in order to obtain $\Delta_{f} H^{\mathrm{Al}_{3} Z r}(298.15 K)$ :

$$
\begin{aligned}
\Delta_{f} H^{A l_{3} Z r}(298.15 K)= & \Delta_{f} H^{A l_{3} Z r}(0 K)+\Delta H^{A l_{3} Z r}(298.15 K)-3 \Delta H^{A l(f c c)}(298.15 K) \\
& -\Delta H^{Z r(h c p)}(298.15 K)+\Delta E_{z p e}^{A l_{3} Z r}
\end{aligned}
$$

where $\Delta E_{z p e}^{A l_{3} Z r}$ is the difference of zero-point energies :

$$
\Delta E_{z p e}^{A l_{3} Z r}=E_{z p e}^{A l_{3} Z r}-3 E_{z p e}^{A l}-E_{z p e}^{Z r}
$$

We have obtained $\Delta_{f} H^{A l_{3} Z r}(0 K)=-184.4 \mathrm{~kJ}^{-\mathrm{mol}^{-1}}$, in agreement with [53, 56-59] (Table 4), and -183.5 kJ.mol ${ }^{-1}$ for $\Delta_{f} H^{A l_{3} Z r}(298.15 K)$. Even if there is a need for an additional experimental determination, our calculations tend to validate the experimental values by $[19,47,49]$ only overestimated by $5 \%$ whereas they seem to invalidate the lowest values by $[43,45]$ as well as the highest one by [50].

For $\Delta H^{A l_{3} Z r}(T)$ (Table 3), Wang et al. [52] and Fischer et al. [53] selected the values of Esin et al. [45, 48] who determined heat contents of $\mathrm{Al}_{3} \mathrm{Zr}$ from adiabatic calorimetry measurements between 300 and $2000 \mathrm{~K}$. Esin's data are not very well documented. In addition the heat capacity values recently reported in [60] are significantly different from Esin's data. On this basis, we decided to redetermine the heat increment of $\mathrm{Al}_{3} \mathrm{Zr}$ at $996.15 \mathrm{~K}$ and at $1176.15 \mathrm{~K}$. The measurements were performed in the TianCalvet high temperature calorimeter described in Part 2. In each run (2 runs for each temperature), 4 small fragments of $\mathrm{Al}_{3} \mathrm{Zr}$ (Alfa Aesar, 99\%) were dropped successively in the initially-empty graphite crucible. The calorimeter was heat calibrated at the beginning of the experiment by dropping several pieces of different masses of synthetic sapphire $\left(\alpha-\mathrm{Al}_{2} \mathrm{O}_{3}\right)$ alumina provided by the U.S. National Bureau of Standards [61]. 
from room temperature into the calorimeter. The process was repeated at least three times and the linearity of the response of the calorimeter was checked. The enthalpy values of $\mathrm{Al}_{2} \mathrm{O}_{3}$ are accurate to $\pm 0.1 \%$ for temperatures lower than $1173 \mathrm{~K}$. The measured increments of $\mathrm{Al}_{3} \mathrm{Zr}$ at 996 and $1176 \mathrm{~K}$ are in agreement with the data reported by Esin [45] and Kleppa and Meschel [47] (Figure 3). They are also well-reproduced below $1500 \mathrm{~K}$ by calculations performed within the harmonic approximation.

According to the Wang's and Fischer's assessments [53] or this work (Table 5), the enthalpy of Reaction (2), corresponding to the $\mathrm{Al}_{3} \mathrm{Zr}$ formation in the calorimeter, is equal to $-216.1,-209.1,-214.5 \pm 5.2 \mathrm{~kJ}^{-\mathrm{mol}^{-1}}$ respectively, in agreement with the measured thermal effect in our tests, equal to $-219.1 \pm 5 \mathrm{~kJ} \cdot \mathrm{mol}^{-1}$.

\subsubsection{Micrographic examinations}

After cooling of the crucible containing the bath, the solidified ingot was longitudinally cut, embedded in resin, and polished. The scanning electron micrographs (SEM) in the back scattered imaging mode showed two different populations of $\mathrm{Al}_{3} \mathrm{Zr}$ (in white on Figure 4) in the lower part of the ingots of characteristic lengths about 50 $\mu \mathrm{m}$ and $5 \mu \mathrm{m}$, whereas in the upper part, no such precipitates could be detected. The absence of chemical contrast through the precipitates suggests that they are homogeneous. Zirconium content in the aluminum-rich phase (i.e. in-between precipitates) could not be quantified regarding its very low value. For the same reason, in the upper part of the bath, the mean zirconium composition could not be measured.

Today there is not a complete understanding of the scenario of the formation of the two populations of precipitates :

- for large precipitates : once the zirconium sample is dropped in liquid, it likely settles down to the bottom of the crucible because of a significant difference in density between solid $\mathrm{Zr}, \mathrm{Al}_{3} \mathrm{Zr}$ and liquid $\mathrm{Al}^{2}$. According to our interpretation, we could expect a complete transformation of the sample into aluminide even it cannot be excluded that zirconium is, even very partially, dissolved, before completely transforming into aluminide. On the SEM images (Figure 4), the largest pieces of aluminide are of typical length of $50 \mu \mathrm{m}$, i.e. much less than that of the original sample $(1000 \mu \mathrm{m})$. Fracturation of $\mathrm{Al}_{3} \mathrm{Zr}$ layer in course of its formation on zirconium substrate was observed by Natanzon et al. [62]. In the Al-Ti system, Sujata et al. [63] explain the mechanism of fracturation of the aluminide by the fact that the $\mathrm{Ti}$ and $\mathrm{Al}_{3} \mathrm{Ti}$ molar volumes, differ significantly. Thus the $\mathrm{Al}_{3} \mathrm{Ti}$ layer formed and grown over solid titanum tries to expand, getting subjected to a state of stress, the degree of which increases with its thickness and the rate of its growth. However, since $\mathrm{Al}_{3} \mathrm{Ti}$ has only a limited ductility, after reaching a critical thickness, this layer can undergo cracking and fissuring under the state of stresses developed due to its tendency to expand. Considering the similarities of $\mathrm{Al}_{3} \mathrm{Ti}$ and $\mathrm{Al}_{3} \mathrm{Zr}$ in terms of crystallographic structures $\left(\mathrm{DO}_{22}\right.$ and $\mathrm{D}_{23}$ resp.), in terms of difference of molar volume with the refractory element

\footnotetext{
${ }^{2} \mathrm{Zr}: \approx 6410 \mathrm{~kg} \cdot \mathrm{m}^{-3}, \mathrm{Al}_{3} \mathrm{Zr}: \approx 4130 \mathrm{~kg} \cdot \mathrm{m}^{-3}$ and liquid $\mathrm{Al}: \approx 2350 \mathrm{~kg} \cdot \mathrm{m}^{-3}$.
} 
(73\% and 64\%, resp.), and in terms of ductility (bulk modulus to shear modulus ratios, 1.25 and 1.20, [64] and Poisson's ratios, 0.18 and 0.17, [64] resp.), an analogous mechanism as described by Sujata for Al-Ti can be assumed for Al$\mathrm{Zr}$.

- for small precipitates : the tabular form of these precipitates is typical of $\mathrm{Al}_{3} \mathrm{Zr}$ growth mainly driven by the preferential migration of some interfaces of high roughness, i.e. (111) and (101), in comparison with more perfect ones, (001). It results for precipitate in a highly anisotropic observed tabular shape [65]. As an overall calorimetry experiment approximately lasts $\approx 24$ hours (6-8 drops and between each drop, about 3 hours), we can assume a re-dissolution of the fractured pieces of $\mathrm{Al}_{3} \mathrm{Zr}$ (coming from the first drops) and then a progressive zirconium enrichment of liquid phase in the bottom part of the ingot until reaching the solubility limit. According to observations performed by Clyne et al. [66] in experimental conditions rather similar to ours (in terms of crucible geometry and aluminum mass), re-dissolution of these $\mathrm{Al}_{3} \mathrm{Zr}$ fragments is a slow process which becomes even slower as the melt composition approaches the zirconium solubility ${ }^{3}$. As the composition of liquid in the bottom part of the ingot is saturated or near saturation, there is possibility of precipitation of dissolved zirconium into aluminide. Another possibility is that these precipitates may have been also produced during the cooling of the sample outside the calorimeter after the end of the experiment. Fan [67] experimentally showed that the area fraction of primary $\mathrm{Al}_{3} \mathrm{Zr}$ precipitating from a liquid phase containing $0.6 \mathrm{wt} \% \mathrm{Zr}$ at $1023 \mathrm{~K}$ is nearly zero only at a cooling rate of $95 \mathrm{~K} . \mathrm{s}^{-1}$ (such a high cooling rate is not reached in our procedure). At lower cooling rates, a non-negligible amount of primary $\mathrm{Al}_{3} \mathrm{Zr}$ is always detected on the micrographs as illustrated by [68].

\subsection{Other experiments at $\approx 1000 \mathrm{~K}$}

\subsubsection{Simulation of the dissolution process}

The simulations of the dissolution processes in the experimental works of Gomozov et al. $[10,11]$ and Turchanin et al. $[8,9,13]$ reported on Figure 5 show that in both cases, complete dissolution of zirconium samples takes place only after several hours, which is an untypical duration in high temperature calorimetry. In addition, it must be noticed that if these calculated durations are only indicative (due to the fact that the shapes of zirconium samples are not known in these studies), our calculations tend to minimise them since the initial sample area is conserved during the simulations. This is in contradiction with the observed experimental durations of the heat effects reported at least by Turchanin et al..

\footnotetext{
${ }^{3}$ This re-dissolution process is likely weakly energetic since no thermal effect associated to this process can be discriminated from the thermograms.
} 


\subsubsection{Micrographic examinations}

After their tests, Gomozov et al. [10,11] performed an X-ray analysis of the bath that did not indicate the presence of aluminide, suggesting a complete dissolution of zirconium in the bath. One possibility is that Gomozov et al. was not able to detect precipitates.

Considering the low concentration of zirconium at the end of the experiment, attention has to be paid regarding the absence of precipitates which may depend of the cutting plan of the ingot for SEM examinations.

Following the simplified approach developed by Clyne et al. [66], we are going to try to estimate the probability of no detection of precipitate in the Gomozov's test. In the limiting situation where all zirconium is transformed into $\mathrm{Al}_{3} \mathrm{Zr}$ precipitates, the number of such precipitates, $N$, in the ingot can be estimated by :

$$
N \approx \frac{V_{\mathrm{Al}_{3} \mathrm{Zr}}}{d_{\mathrm{Al} l_{3} \mathrm{Zr}}^{3}}=\frac{m_{\mathrm{Al}_{3} \mathrm{Zr}}}{\rho_{\mathrm{Al}_{3} Z r} d_{\mathrm{Al} l_{3} \mathrm{Zr}}^{3}}
$$

where $V_{A l_{3} Z r}, m_{A l_{3} Z r}, \rho_{A l_{3} Z r}$ and $d_{A l_{3} Z r}$ are, respectively, the total volume occupied by the precipitates, the corresponding mass, the $\mathrm{Al}_{3} \mathrm{Zr}$ density, and the typical dimension of one precipitate (assumed to be cubic).

Assuming that all the precipitates are oriented parallel to the cutting plan, the probability $p$ of any given precipitate to be in a longitudinal section of the ingot (to simplify the problem, instead of a cylinder of length $L$ and radius $R$, we will consider a parallepipedic ingot of lengths $L$ and $\sqrt{\pi} R$ ) can be estimated by :

$$
p \approx \frac{\sqrt{\pi} R L d_{A l_{3} Z r}}{\pi R^{2} L}=\frac{d_{A l_{3} Z r}}{\sqrt{\pi} R}
$$

The probability of not observing a given precipitate is $1-p$ and the probability of not observing any of the $N$ precipitates is $(1-p)^{N}$.

If it is assumed that zirconium was completely transformed into aluminide, the volume fraction of these at the end of the Gomozov's test was $\approx 2 \times 10^{-3}$. The probabilities of not observing any of the $N$ precipitates of dimensions $d_{A l_{3} Z r}=50$ and 5 $\mu m$ (assumed to be of similar sizes that ours observed at $996 \mathrm{~K}$ ), as a function of the precipitate volume fraction are reported on Figure 6. This qualitative analysis shows that for a precipitate volume fraction of $2.0 \times 10^{-3}$, whatever the longitudinal cut, if they existed, precipitates should have been detected by SEM.

This analysis suggests that the absence of precipitates as claimed by Gomozov was likely representative of the overall ingot ${ }^{4}$. Consequently, there is a contradiction with the conclusion drawn from the simulation of the dissolution process. A possibility is a typographic error in the Gomozov's original publication regarding the $S / V$ value $\left(=1 \mathrm{~m}^{-1}\right.$ in $\left.[10,11]\right)$ since the authors, aware of the possibility of formation of zirconium aluminide, explicitly wrote to take into account the empirical rules provided by

\footnotetext{
${ }^{4}$ Nevertheless Gomozov et al. $[10,11]$ should have observed aluminides located in the lower part of the ingot, resulting of the cooling process.
} 
Eremenko et al. [24], i.e. $S / V=10 \mathrm{~m}^{-1}$. With this corrected value, the dissolution time is reduced to $\approx 1$ hour (Figure 5), which is a typical duration for high temperature calorimetry experiments.

\subsection{Enhancing the dissolution process}

By examining Equation (11), different experimental parameters can be modified in order to enhance the kinetics of the dissolution process. A typical dissolution time of $\approx$ 1 hour for each drop is usually required to perform a complete run within one day. The first parameter is obviously temperature in order to increase the $C_{s}-C$ term. Figure 7 where the different solubility measurements are reported shows that significant temperature increase is required to enhance the dissolution process through this term. Liquid properties $\left(v, D_{0}\right)$ are also modified with increasing temperature but it is of second order in comparison with $C_{s}-C$. For our experimental conditions in terms of aluminum and zirconium masses, the effect of increasing temperature in the simulations (Figure 8) show that temperatures higher than $1100 \mathrm{~K}$ would be necessary.

We can also notice that as more zirconium samples are dropped into the liquid, $C$ increases and consequently the $C_{s}-C$ term and the dissolution kinetics decrease. We have reported (Figure 9) the effect of the initial zirconium concentration of the bath at $1173 \mathrm{~K}$. The initial concentration must not exceed $0.4 \mathrm{C}_{s}$ to have the required duration.

At least, it is possible to optimize the geometrical parameters of the sample in order to increase the $S / V$ ratio. At $996 \mathrm{~K}$, Figure 10 shows that a significant increase of this parameter is required to reach reasonable dissolution times.

Finally, the model allows to derive some recommendations in terms of experimental conditions to improve the dissolution process. These recommendations are consistent with the empirical rules derived by Eremenko et al. [24].

\subsection{Other solutes}

The previous analysis shows that when the solubility of the solute in the solvent is low at the calorimeter temperature, the dissolution kinetics is strongly reduced. Our dissolution model allows "to test" liquid aluminum as solvent for different metals and to produce some recommendations. The solubilities of some transition elements in liquid aluminum as well as some properties are reported in Table 6 .

Finally, according to our experimental conditions at $996 \mathrm{~K}$ in terms of sample and bath masses (with $S / V=0.8 \mathrm{~m}^{-1}$ ), we have simulated (Figure 11) the dissolution, at $1023 \mathrm{~K}$, of a sample for different transition metals. We observe that liquid aluminum could be an adequate solvent for chromium, iron, cobalt and nickel whereas for titanium and vanadium, it appears to be marginally suitable. These conclusions are fully in agreement with experimental observations performed by Darby et al. [69] about the use of aluminum as solvent in high temperature calorimetry.

\section{Conclusion}

A critical analysis of the experimental data on the zirconium dissolution in liquid aluminum at temperatures around $1000 \mathrm{~K}$ obtained by different authors in the framework of calorimetry experiments is performed. It is supported by the development of 
the dissolution kinetics model which is presented in this paper. We show that probably most of the experiments interpreted in terms of dissolution must be considered in terms of (partial or total) transformation of zirconium into zirconium aluminide $\left(\mathrm{Al}_{3} \mathrm{Zr}\right)$.

Considering this point, we confirm as already indicated in [20] that the experimental values for standard enthalpies of formation in the Co-Zr [10, 11], Cu-Zr [12, 14], $\mathrm{Ni}-\mathrm{Zr}[6,9,14]$ and $\mathrm{U}-\mathrm{Zr}[7]$ systems using solution calorimetry in an aluminum bath at $\approx 1000 \mathrm{~K}$ should be taken with caution.

Klein et al. [70] showed that it is possible to dissolve zirconium at room temperature in an acid mixture containing hydrofluoric acid. In parallel silver may be dissolved in nitric acid. The acid bath calorimetric measurements of $\mathrm{Ag}, \mathrm{Zr}$, and $\mathrm{AgZr}$ recently performed in our laboratory will be presented in a future paper. From the solution enthalpy of $\mathrm{AgZr}$ in aluminum at $1000 \mathrm{~K}$, we will be able to propose an estimate of the solution enthalpy of zirconium in liquid aluminum at this temperature. 
Table 1: Solution enthalpies $\left(\mathrm{kJ}^{\mathrm{m}} \mathrm{mol}^{-1}\right)$ of zirconium in liquid aluminum at infinite dilution near $1000 \mathrm{~K}-\mathrm{The}$ references states are solid zirconium at $298.15 \mathrm{~K}$ and liquid aluminum at temperature. $\left(^{*}\right)$ The more recent values of Turchanin et al., according to the authors [14], are considered to be a refinement of the previoulsy published ones.

\begin{tabular}{c|cc|c}
\hline Authors & Temperature $(\mathrm{K})$ & $\mathrm{x}_{Z r}$ & $\Delta_{\text {sol }} H^{\infty}(Z r)$ \\
\hline Ansara et $a l$. [6] & 984 & $\leq 0.0014$ & -212.4 \\
Nagarajan et al. $[7]$ & 991 & $\leq 0.0267$ & $-220.3 \pm 9.5$ \\
Turchanin et al. $[8,9,13]$ & 1026 & $\leq 0.0044$ & $-217.4 \pm 8.5$ \\
Gomozov et $a l .[10,11]$ & 1030 & $\leq 0.0006$ & $-203.3 \pm 4.9$ \\
Turchanin et al. $[12,14]$ & 1022 & $\leq 0.0055$ & $-235.0 \pm 4.3^{*}$ \\
Decreton et $a l .[20]$ & 996 & $\leq 0.0022$ & $-221.5 \pm 5.8$ \\
\hline
\end{tabular}


Table 2: Aluminum and zirconium masses involved in the dissolution experiments, initial geometries of the samples and typical dissolution time by drop. ${ }^{(1)}$ See text of 4.1. ${ }^{(2)}$ Information unknown.

\begin{tabular}{c|cccc}
\hline Authors & $\mathrm{Zr}(\mathrm{mg})$ & $\mathrm{Al}(\mathrm{g})$ & $(\mathrm{S} / \mathrm{V})_{\text {init }}\left(\mathrm{m}^{-1}\right)$ & Time $(\mathrm{s})$ \\
\hline Ansara et $a l$. [6] & $-(2)$ & $-(2)$ & $-(2)$ & $-(2)$ \\
Nagarajan et al. $[7]$ & $11-13$ & 0.66 & $-(2)$ & $-(2)$ \\
Turchanin et $a l .[8,9,13]$ & $45-70$ & $30-40$ & 10 & 3600 \\
Gomozov et al. $[10,11]$ & $30-50$ & 54 & $1\left({\left.\mathrm{ou} 10^{(1)}\right)}_{-}\right.$ & $-(2)$ \\
Turchanin et al. $[12,14]$ & $30-40$ & $60-80$ & $-(2)$ & $1500-2400$ \\
Decreton et al. $[20]$ & $3-4$ & 9.1 & 0.83 & 1400 \\
\hline
\end{tabular}


Table 3: Thermodynamic properties of $\mathrm{Al}_{3} \mathrm{Zr}^{(1)}$ Published value, $-170.4 \mathrm{~kJ} \cdot \mathrm{mol}^{-1}$, corrected with the SGTE data [71]

\begin{tabular}{|c|c|c|c|}
\hline Author & & Method & Comment \\
\hline & $\Delta_{\mathbf{f}} \mathbf{H}^{\mathrm{AI}_{3} \mathbf{Z r}}(\mathbf{0 K})$ & & \\
\hline$[53,56-59,72,73]$ & {$[-196.4-187.9]$} & DFT & Values at $0 \mathrm{~K}$, zpe not included \\
\hline \multirow[t]{2}{*}{ This work } & -184.4 & DFT & Values at $0 \mathrm{~K}$, zpe not included \\
\hline & $\Delta_{\mathrm{f}} \mathrm{H}^{\mathrm{Al}_{3} \mathrm{Zr}}(298.15 \mathrm{~K})$ & & \\
\hline Alcock et al. [42] & $-177.6 \pm 6.7$ & calorimetry & inhomogeneous sample \\
\hline Kematick et al. [43] & -163 & Knudsen cell spect. & $1300-1673 \mathrm{~K}$ \\
\hline Esin et al. [45] & $-167.9^{(1)}$ & adiabatic calo. & 1970 K, Hess'cycle \\
\hline Meschel et al. [47] & $-193.6 \pm 5.2$ & direct calo. & $1473 \mathrm{~K}$, complete reaction \\
\hline Weihs et $a l$. [49] & $-186 \pm 14$ & DSC & multilayer foil sample \\
\hline Fisher et al. [50] & $-212 \pm 8$ & DSC & multilayer foil sample \\
\hline Saunders et al. [51] & -162.5 & ass. & based on [43] \\
\hline Murray et al. [44] & $-196 \pm 4$ & ass. & ass. of [43], $2^{\text {nd }} \& 3^{\text {rd }}$ laws \\
\hline Witusiewicz al. [19] & -193.5 & disso. calo. & 2045 K, Hess'cycle \\
\hline Wang et al. [52] & -194.2 & ass. & based on [47] \\
\hline Fischer et al. [53] & -187.2 & ass. & based on DFT value at $0 \mathrm{~K}$ [59] \\
\hline Tamim et al. [54] & $-186.5 /-177.3$ & ass. & 2 models \\
\hline This work & $\begin{array}{c}-183.5 \\
\Delta \mathbf{H}^{\mathbf{A} \mathbf{l}_{3} \mathbf{Z r}}(\mathbf{T})\end{array}$ & calc. & DFT value at $0 \mathrm{~K}+$ phonon calc. \\
\hline Esin et $a l .[45]$ & see Fig. 3 & adiabatic calo. & $300-2000 \mathrm{~K}$ \\
\hline Serebrennikov et al. [48] & see Fig. 3 & adiabatic calo. & $300-2000 \mathrm{~K}$ \\
\hline Meschel et al. [47] & see Fig. 3 & calo. & $1473 \mathrm{~K}$ \\
\hline \multirow[t]{2}{*}{ This work } & see Fig. 3 & drop calo. & $996,1176 \mathrm{~K}$ \\
\hline & $\begin{array}{l}\text { see Fig. } 3 \\
\mathbf{C}_{\mathbf{p}}^{\mathbf{A l}_{3} \mathbf{Z r}}(\mathbf{T})\end{array}$ & calc. & Phonon calc. \\
\hline Esin et $a l .[45]$ & & & Derivative of $\Delta H^{A l_{3} Z r}(T)$ \\
\hline Serebrennikov et al. [48] & & & Derivative of $\Delta H^{A l_{3} Z r}(T)$ \\
\hline Kemsies et al. [60] & & DSC & $300-825 \mathrm{~K}$ \\
\hline
\end{tabular}




\begin{tabular}{c|ccc} 
Table 4: Enthalpy of formation of $\mathrm{Al}_{3} \mathrm{Zr}\left(\mathrm{kJ} . m o l^{-1}\right)$ at $0 \mathrm{~K}$ calculated by DFT in different studies \\
\hline Author & Code & Functional & Value \\
\hline Ghosh et $a l$. [72] & VASP & GGA-PW & -196.4 \\
Zhang et $a l$. [73] & ABINIT & - & -158.4 \\
Wang et $a l$. [56] & VASP & GGA-PBE & -187.1 \\
Mihakovic et $a l$. [57] & VASP & GGA-PW91 & -188.7 \\
Saal et $a l$. [58] & VASP & GGA-PBE & -188.4 \\
Duan et $a l$. [59] & CASTEP & GGA-PBE & -187.1 \\
Colinet et $a l$. [53] & VASP & GGA-PBE & -187.9 \\
This work & Quantum Espresso & GGA-PBE & -184.4 \\
\hline
\end{tabular}


Table 5: Numerical values for the calculation of $\Delta H_{2}(T)$ for $\mathrm{T}=996.15 \mathrm{~K}$ involved in reaction (2), according to the Wang's [52], the Fischer's [53] assessments and this work. ${ }^{1}[47],{ }^{2}[71],{ }^{3}$ This work. All values are given in $\mathrm{kJ}^{\mathrm{mol}}{ }^{-1}$

\begin{tabular}{c|cccc}
\hline Quantities & T(K) & Wang et al. [52] & Fischer et al. [53] & This work \\
\hline$\Delta_{f} H^{A l_{3} Z r}(T)$ & 298.15 & -194.2 & -187.2 & $-193.2 \pm 5.2^{1}$ \\
$\Delta H^{A l}(T)$ & 996.15 & 30.8 & 30.8 & $30.8^{2}$ \\
$\Delta H^{A l_{3} Z r}(T)$ & 996.15 & 70.5 & 70.5 & $71.1 \pm 0.4^{3}$ \\
\hline$\Delta H_{2}(T)$ & 996.15 & -216.1 & -209.1 & $-214.5 \pm 5.2$ \\
\hline
\end{tabular}


Table 6: Solubilities $\left(\mathrm{C}_{s}\right.$ in wt.\%) in liquid aluminum, diffusion coefficients in liquid aluminum $\left(\mathrm{D}_{0}\right.$ in $\mathrm{m}^{2} \cdot \mathrm{s}^{-1}$ ) for different transition metals at $1023 \mathrm{~K}$ from Eremenko et al. [37] and densities at the melting temperature from different authors. $.^{(1)}[74] .{ }^{(2)}[75] .{ }^{(3)}[76] .{ }^{(4)}[77] .{ }^{(5)}[78] .{ }^{(6)}[79]$.

\begin{tabular}{c|ccc}
\hline Metal & $\mathrm{C}_{s}$ & $\mathrm{D}_{0}$ & $\rho_{l, M}$ \\
\hline Titanium & 0.33 & $2.9510^{-9}$ & $4100^{(1)}$ \\
Vanadium & 0.46 & $1.0810^{-9}$ & $5460^{(2)}$ \\
Chromium & 1.29 & $2.6710^{-9}$ & $6160^{(3)}$ \\
Iron & 3.40 & $3.9010^{-9}$ & $6994^{(4)}$ \\
Cobalt & 2.40 & $3.0210^{-9}$ & $7989^{(5)}$ \\
Nickel & 13.5 & $4.3010^{-9}$ & $7850^{(6)}$ \\
\hline
\end{tabular}




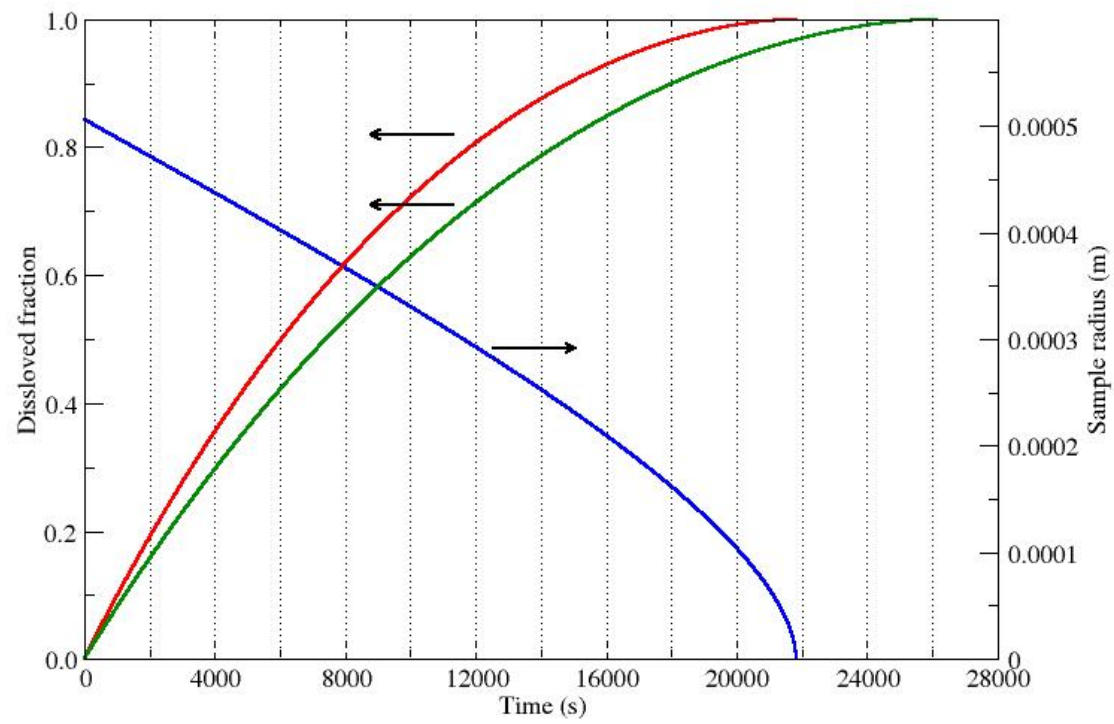

Figure 1: Calculated evolutions of the dissolved fraction and the zirconium sample radius in our experimental conditions at $996 \mathrm{~K}$ (red line : Churchill's correlation, green line : Yovanovich's correlation) $\left(S / V=0.8 \mathrm{~m}^{-1}\right.$, $\left.\mathrm{m}_{\text {sample }}=3.5 \mathrm{mg}, \mathrm{m}_{\text {bath }}=9.1 \mathrm{~g}\right)$. 


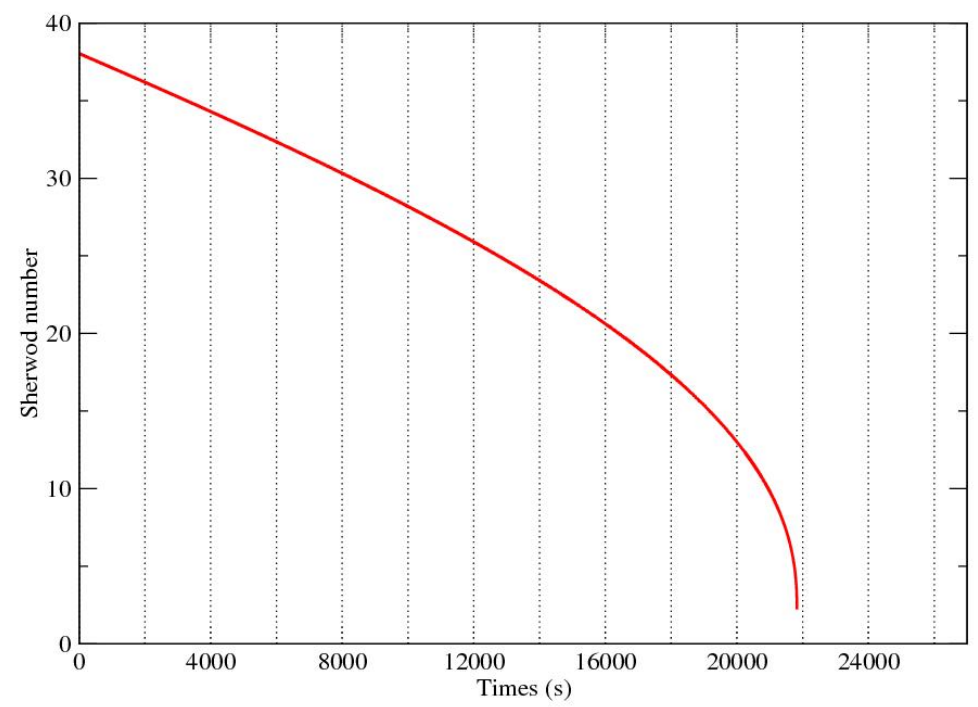

Figure 2: Calculated evolution of Sherwood number in our experimental conditions at $996 \mathrm{~K}(S / V=0.8$ $\mathrm{m}^{-1}, \mathrm{~m}_{\text {sample }}=3.5 \mathrm{mg}, \mathrm{m}_{\text {bath }}=9.1 \mathrm{~g}$, Churchill's correlation). 


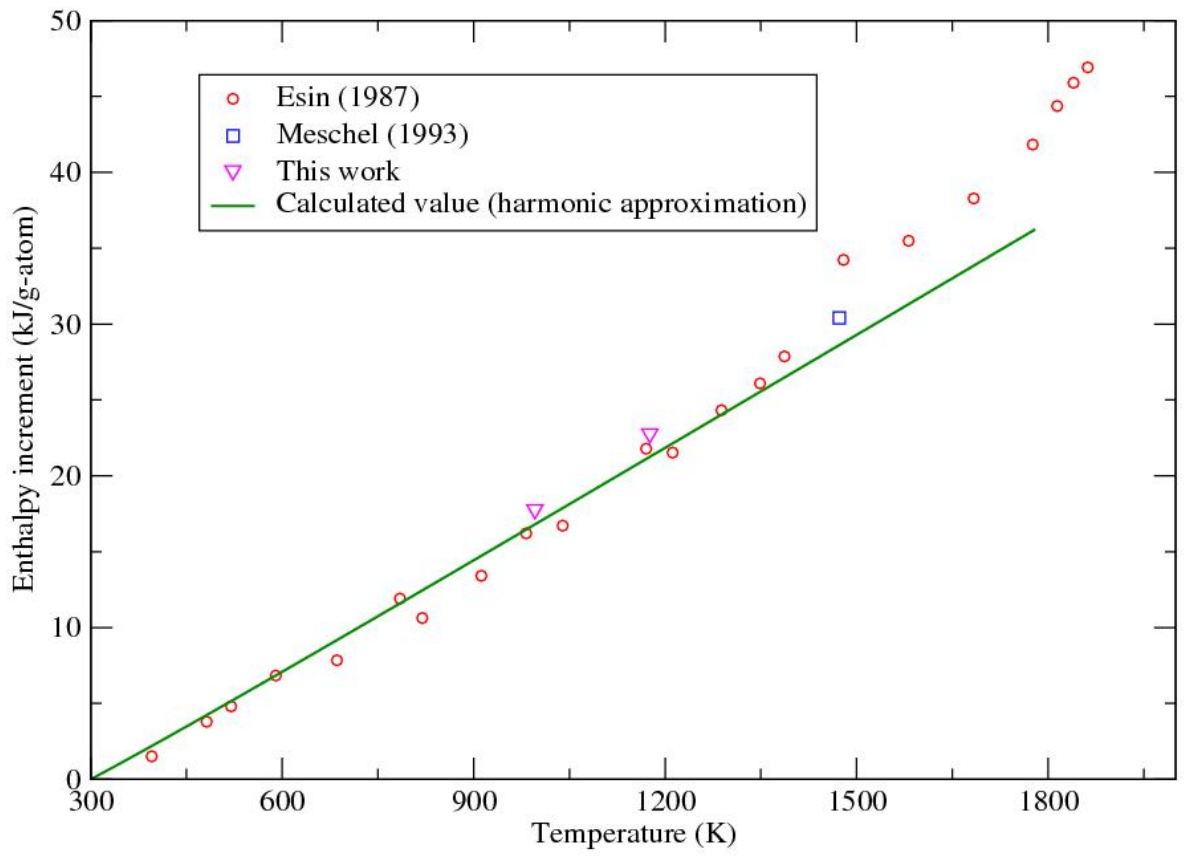

Figure 3: Enthalpic increments of $\mathrm{Al}_{3} \mathrm{Zr}$ measured in this study and comparison with other past data and calculations performed within the harmonic approximation 

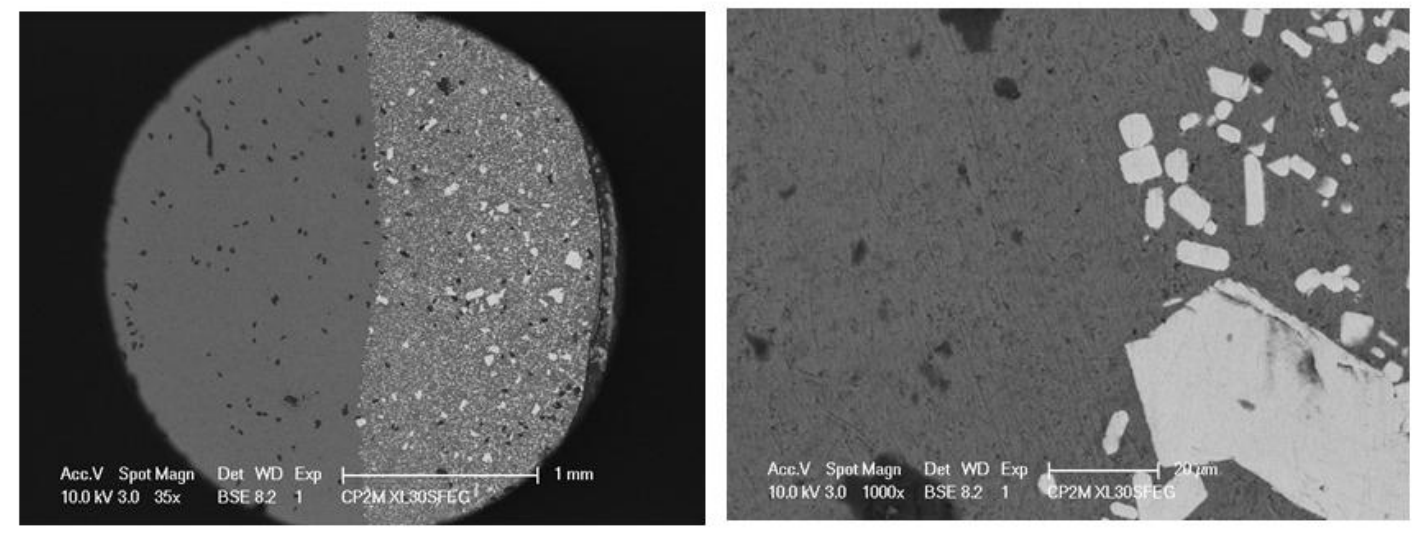

Figure 4: Experiment at $996 \mathrm{~K}$, SEM backscattered electron image of (left) the bath and (right) the lower part of the bath after cooling. 


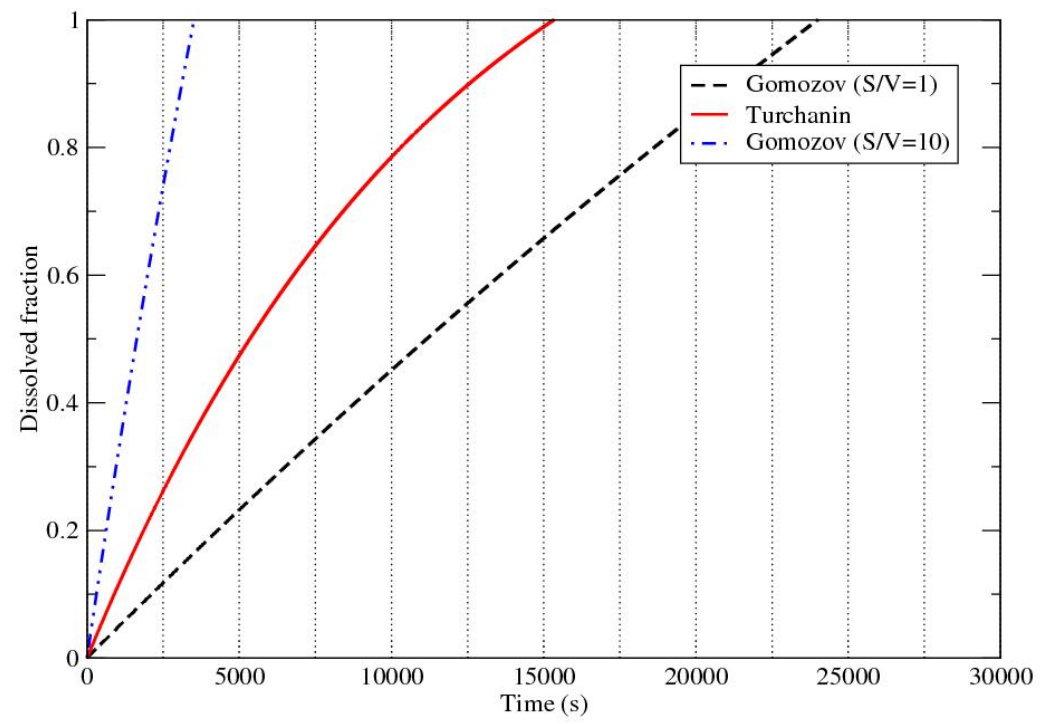

Figure 5: Calculated evolutions of the dissolved fractions in the Turchanin's $[8,9,13]$ and Gomozov's conditions $[10,11]$. 


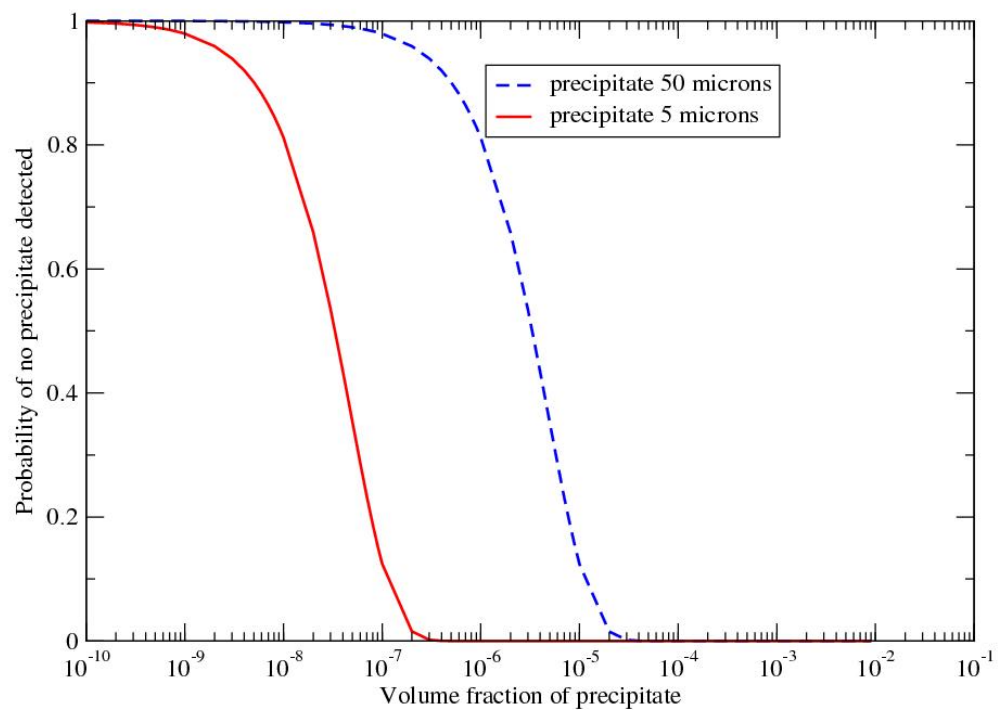

Figure 6: Evolution of probability of no precipitate detected for two precipitate sizes, as a function of the volume fraction of precipitate. 


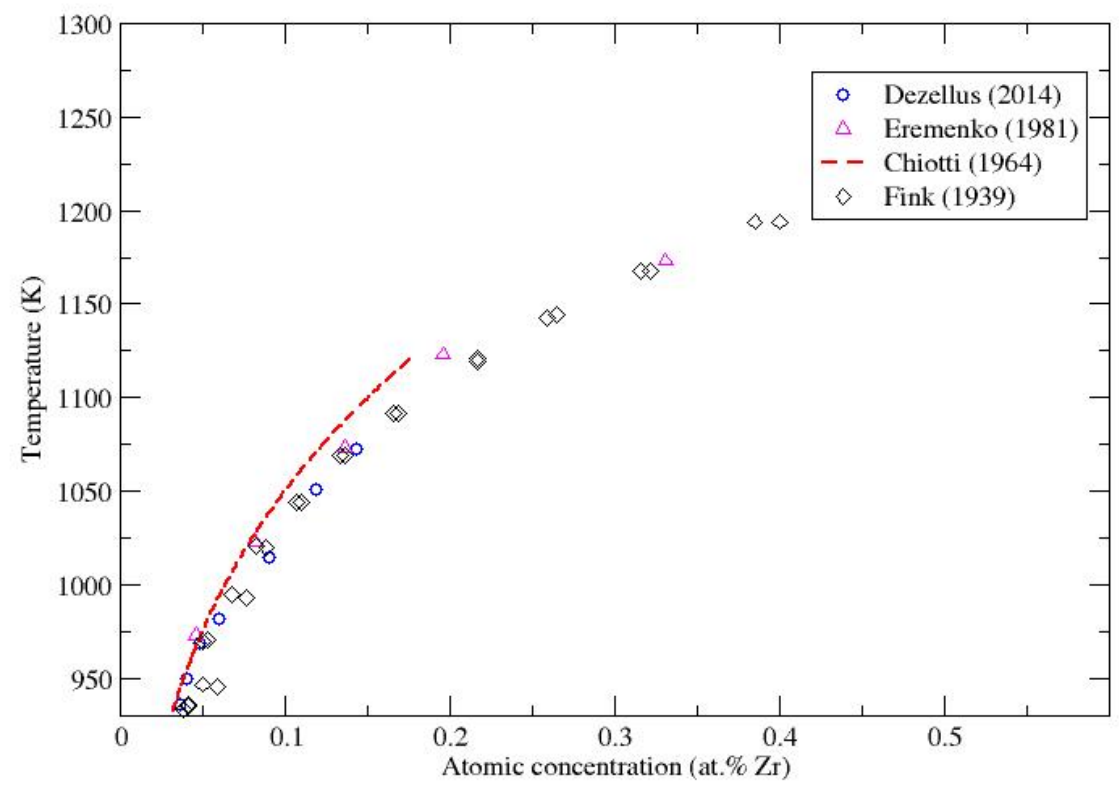

Figure 7: Solubility limit of $\mathrm{Zr}$ in liquid $\mathrm{Al}$ measured by different authors [22, 23, 38, 39]. 


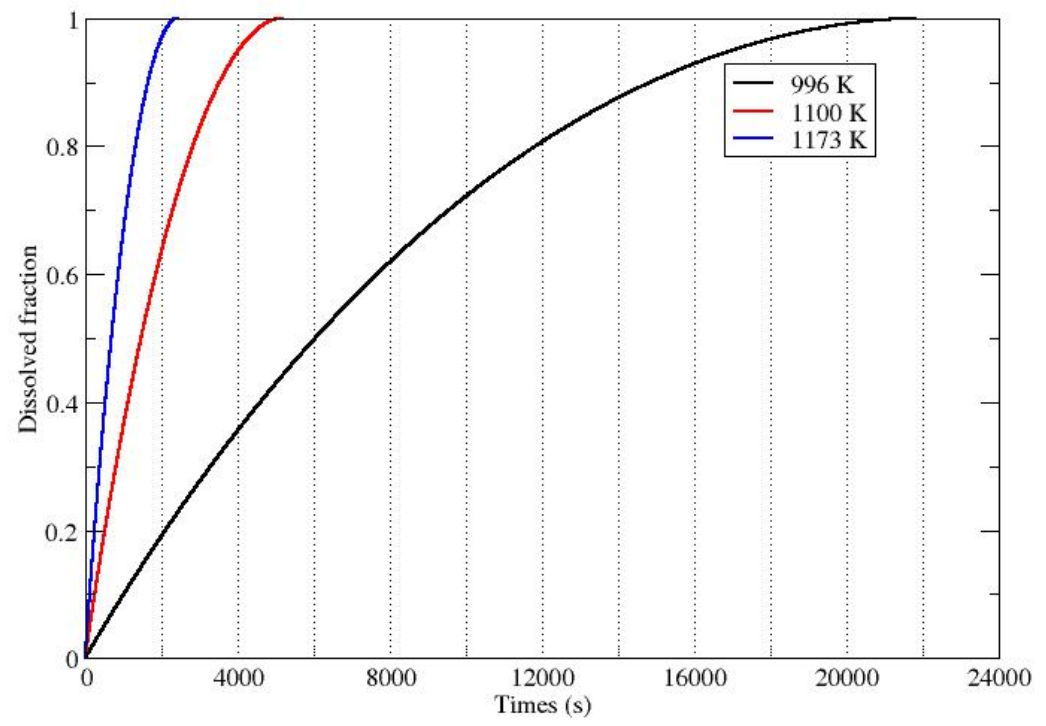

Figure 8: Calculated evolutions of the dissolved fraction at different temperatures $\left(S / V=0.8 \mathrm{~m}^{-1}\right.$, $\mathrm{m}_{\text {sample }}=3.5 \mathrm{mg}, \mathrm{m}_{\text {bath }}=9.1 \mathrm{~g}$ ). 


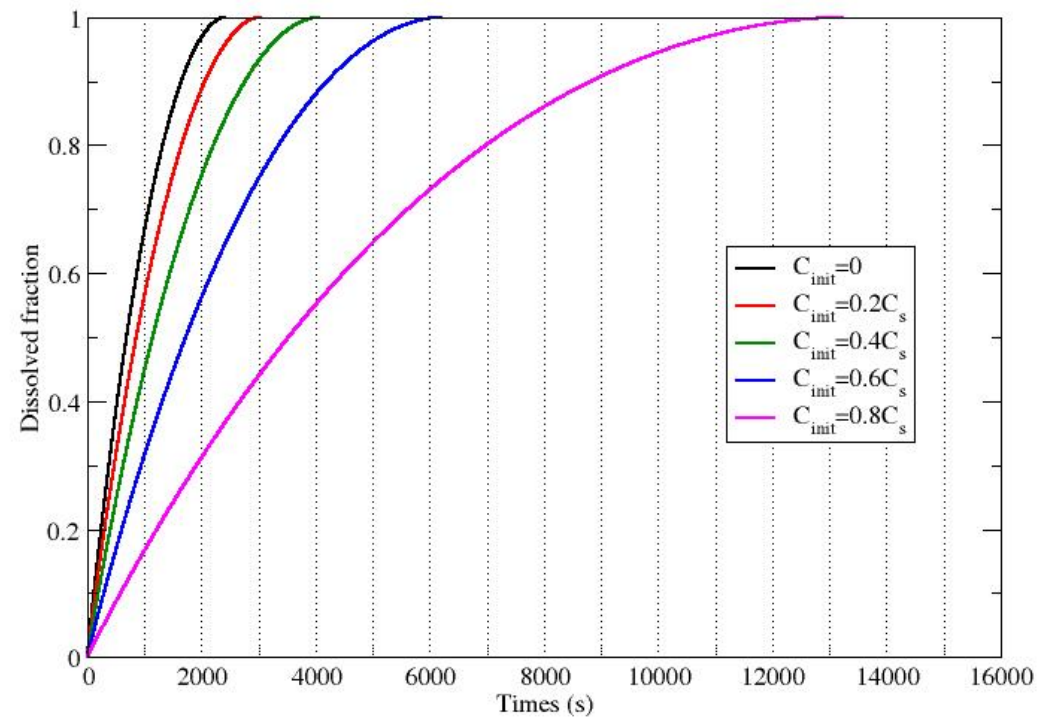

Figure 9: Calculated evolutions of the dissolved fractions at $1173 \mathrm{~K}$ for different initial zirconium compositions in the bath $\left(S / V=0.8 \mathrm{~m}^{-1}, \mathrm{~m}_{\text {sample }}=3.5 \mathrm{mg}, \mathrm{m}_{\text {bath }}=9.1 \mathrm{~g}\right)$. 


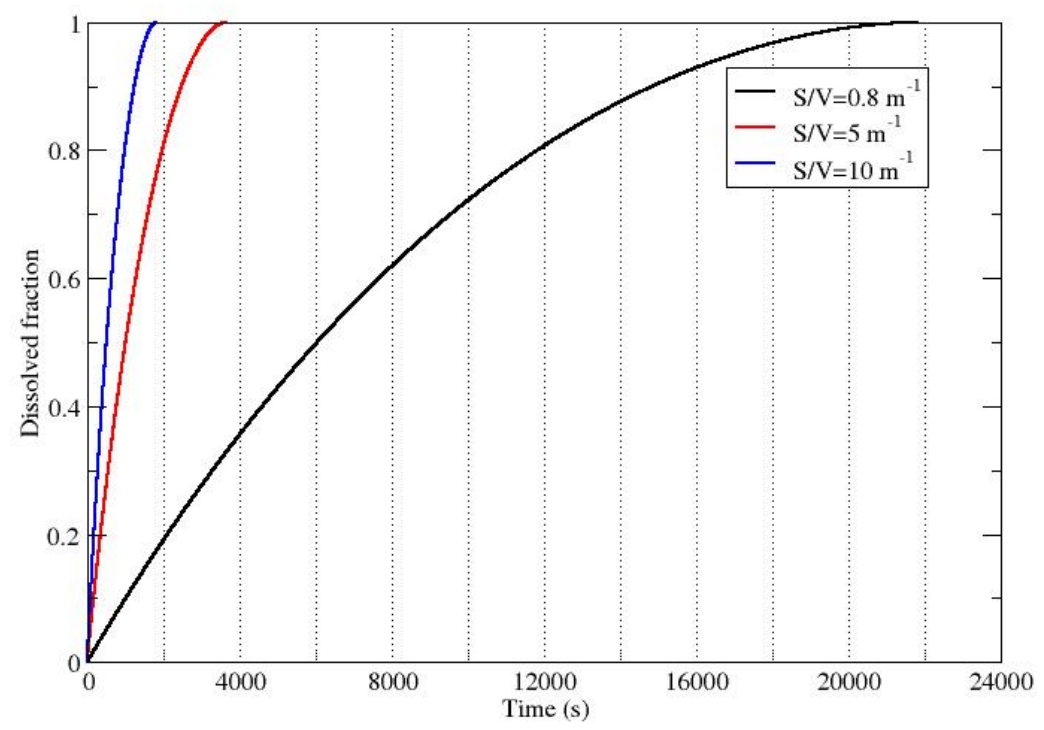

Figure 10: Calculated evolutions of the dissolved fraction for different $S / V$ at $996 \mathrm{~K}$ and comparison with the simulation of our test for $S / V=0.8 \mathrm{~m}^{-1}$. 


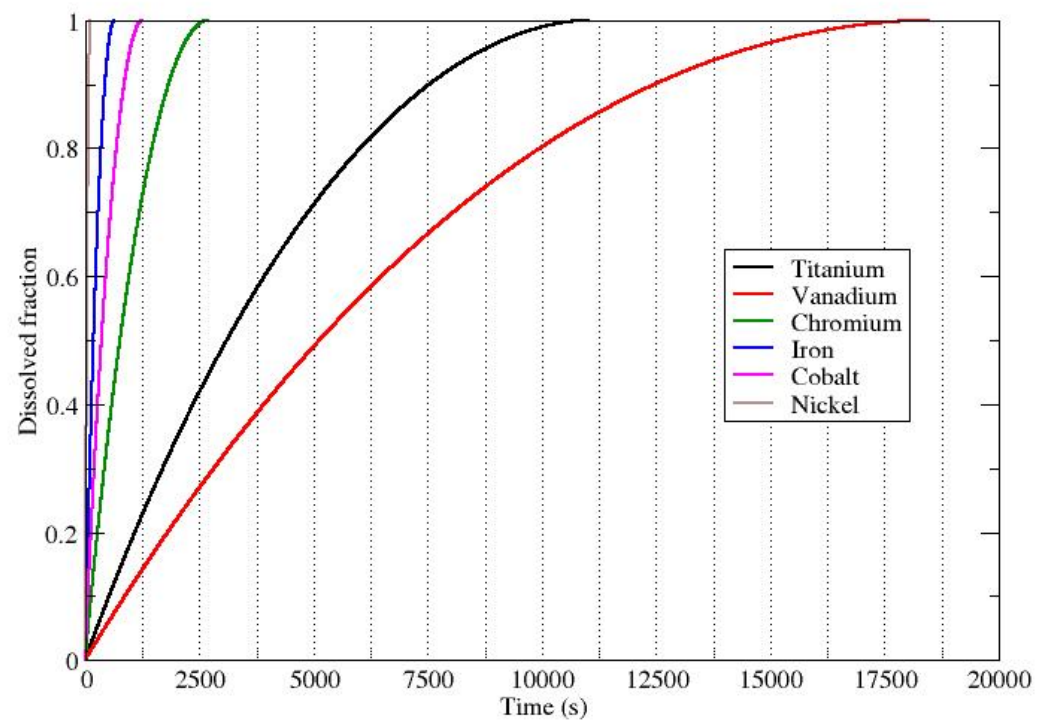

Figure 11: Calculated evolution of the dissolved fraction at $1023 \mathrm{~K}$ for different transition metals $(S / V=0.8$ $\mathrm{m}^{-1}, \mathrm{~m}_{\text {sample }}=3.5 \mathrm{mg}, \mathrm{m}_{\text {bath }}=9.1 \mathrm{~g}$ ). 


\section{References}

[1] A. Yassin, R. Castanet, J. Alloy. Compd. 314 (2001) 160-166.

[2] A. Yassin, M. Gilbert, R. Castanet, J. Alloy. Compd. 322 (2001) L19-L22.

[3] V. Sudavtsova, G. Batalin, Rasplavy 90 (1990) 88.

[4] A. Bouhajib, A. Nadiri, R. Yacoubi, A. Castanet, Phys. Chem. Liquids 38 (2000) 261.

[5] C. Colinet, J. Alloy. Compd. 220 (1995) 76-87.

[6] I. Ansara, A. Pasturel, K. Buschow, Phys. Status Solidi 69 (1982) 447-453.

[7] K. Nagarajan, R. Babu, C. Mathews, J. Nucl. Mater. 203 (1993) 221-223.

[8] A. Zubkov, A. Turchanin, I. Tomilin, Ind. Lab. 61 (1995) 544-547.

[9] A. Turchanin, I. Tomilin, A. Inoue, A. Zubkov, Mater. Sci. Eng. A 226-228 (1997) 487-490.

[10] P. Gomozov, Y. Zasypalov, B. Mogutnov, Russ. J. Phys. Chem. 60 (1986) 11221124.

[11] P. Gomozov, Y. Zasypalov, B. Mogutnov, Zurnal fizicheskoi khimii 60 (1986) $1865-1867$.

[12] A. Turchanin, I. Tomilin, Ber. Bunsen. Phys. Chem. 102 (1998) 1252-1258.

[13] A. Turchanin, I. Tomilin, A. Zubkov, Mat. Sci. Forum 235-238 (1997) 367-372.

[14] A. Turchanin, I. Tomilin, A. Inoue, A. Zubkov, Mat. Sci. Forum 269-272 (1998) $565-570$.

[15] V. Sudavtsova, G. Batalin, V. Tutevich, Russ. Metall. (1985) 183-185.

[16] G. Batalin, E. Beloborodova, V. Nerubashchenko, A. Shlapak, Russ. Metall. 1 (1981) 61-63.

[17] V. Sudavtsova, N. Podoprigora, Powder Metall. and Met. C. 48 (2009) 83-87.

[18] Y. Esin, N. Bobrov, M. Petrushevskii, P. Geld, Izv. Akad. Nauk SSSR, Metally 5 (1974) 104-109.

[19] V. Witusiewicz, U. Stolz, I. Arpshofen, F. Sommer, Z. Metallkde. 89 (1998) 704-713.

[20] A. Decreton, P. Benigni, J. Rogez, G. Mikaelian, M. Barrachin, M. LomelloTafin, C. Antion, A. Janghorban, E. Fischer, J. Nucl. Mater. 465 (2015) 849-856.

[21] G. Kidson, G. Miller, J. Nucl. Mater. 12 (1964) 61-69. 
[22] O. Dezellus, B. Gardiola, J. Andrieux, J. Phase Equilib. Diff. 35 (2014) 120-126.

[23] V. Eremenko, Y. Natanzon, V. Titov, Russ. Metall. (1981) 204-208.

[24] V. Eremenko, Y. Natanzon, V. Dybkov, J. Less-Common Met. 50 (1976) 29-48.

[25] S. Yatsenko, N. Sabirzyanov, A. Yatsenko, J. Phys. 98 (2008) 062032.

[26] A. Bejan, Convection Heat Transfer, Fourth Edition, Wiley, 2013.

[27] S. Churchill, Chem. Eng. Commun. 24 (1983) 339-352.

[28] P. Quested, R. Morrell, A. Dinsdale, L. Chapman, in: Proceedings of the 5th Decennial International Conference on Solidification Processing, Old Windsor, July 2017.

[29] J. Wessing, J. Brillo, Metallurgical and Materials Transactions A 48 (2017) 868882.

[30] Y. Plevachuk, I. Egry, J. Brillo, D. Holland-Moritz, I. Kaban, International Journal Mat. Res. 98 (2007) 107-111.

[31] O. Redlich, A. Kister, Industrial and Engineering Chemistry 40 (1948) 345-348.

[32] M. Yovanovich, ASME HTD 82 (1987) 121-129.

[33] V. Zaitsev, A. Polyanin, Exact Solutions for Ordinary Differential Equations, Second Edition, Chapman and Hall, 2003.

[34] M. Assael, K. Kakosimos, R. Banish, J. Brillo, I. Egry, R. Brooks, P. Quested, K. Mills, A. Nagashima, Y. Sato, W. Wakeham, J. Phys. Chem. Ref. Data 35 (2006) 285-300.

[35] X. Lu, M. Selleby, B. Sundman, Calphad 29 (2005) 68-89.

[36] T. Ishikawa, P. Paradis, T. Itami, S. Yoda, Meas. Sci. Technol. 16 (2005) 443-451.

[37] V. Eremenko, Y. Natanzon, V. Dybkov, Fiziko-Khimicheskaya Mekhanika Materialov 20 (1984) 3-9.

[38] W. Fink, L. Willey, T Am. I. Min. Met. Eng. 133 (1939) 69-80.

[39] P. Chiotti, P. Woerner, J. Less-Common Met. 7 (1964) 111-119.

[40] T. Andreescu, O. Mushkarov, L. Stoyanov, Geometric Problems on Maxima and Minima, Birkhauser, 2013.

[41] B. Taylor, C. Kuyatt, Guidelines for Evaluation and Expressing the Uncertainty of NIST Measurement Results, Technical Report NIST Technical Note 1297, NIST, 1994.

[42] C. Alcock, K. Jacob, S. Zador, Atom. Energy Rev. 14 (1976) 7-65. 
[43] R. Kematic, H. Franzen, Journal of Solid State Chemistry 54 (1984) 226-234.

[44] J. Murray, A. Peruzzi, J. Abriata, J. Phase Equilib. 13 (1992) 277-291.

[45] Y. Esin, N. Serebrennikov, E. Pletneva, V. Kapustkin, Izv. Vuz., Chern. Metall. 10 (1987) $1-3$.

[46] J. Elliott, M. Gleiser, Thermochemistry for Steelmaking, volume 1, AddisonWesley Pub. Co., 1960.

[47] S. Meschel, O. Kleppa, J. Alloy. Compd. 191 (1993) 111-116.

[48] N. Serebrennikov, E. D. Pletneva, Y. Esin, Izv. Vyssh. Ucheb. Zaved. Chernaia. Metall. 2 (1987) 133-134.

[49] T. Weihs, T. Barbee, M. Wall, MRS Symposium Proceedings 82 (1995) 21-26.

[50] K. Fisher, S. Barron, M. Bonds, R. Knepper, K. Livi, G. Campbell, N. Browning, T. P. Weihs, J. Appl. Phys. 114 (2013) 243509.

[51] N. Saunders, Z. Metallkde. 80 (1989) 894-903.

[52] T. Wang, Z. Jin, J. Zhao, J. Phase Equilib. 22 (2001) 544-551.

[53] E. Fischer, C. Colinet, J. Phase Equilib. Diff. 36 (2015) 404-413.

[54] R. Tamim, K. Mahdouk, J. Therm. Anal. Calorim. 131 (2017) 1-14.

[55] P. Giannozzi, S. Baroni, N. Bonini, M. Calandra, R. Car, C. Cavazzoni, D. Ceresoli, G. Chiarotti, M. Cococcioni, I. Dabo, J. Phys.: Condens. Matter 21 (2009) 395502.

[56] J. Wang, S. Shang, Y. Wang, Z. Mei, Y. Liang, Y. Du, Z. Liu, Calphad 35 (2011) $562-573$.

[57] M. Mihalkovic, M. Widom, co workers, Alloy Database from http://alloy.phys.cmu.edu/., 2011.

[58] J. Saal, S. Kirklin, M. Aykol, B. Meredig, C. Wolverton, JOM 65 (2013) 15011509.

[59] Y. Duan, B. Huang, Y. Sun, M. Peng, S. Zhou, J. Alloy. Compd. 590 (2014) $50-60$.

[60] R. Kemsies, B. Milkereit, O. Kessler, Calorimetry on Pure Substances and Complex Non-Equilibrium Al-Systems, GTT Workshop 2016, 2016.

[61] G. Uriano, National Bureau of Standards Certificate - Standard Reference Material 720 Synthetic Sapphire $\left(\alpha-\mathrm{Al}_{2} \mathrm{O}_{3}\right)$, Technical Report, NBS, 1982.

[62] Y. Natanzon, V. Petrishchev, Poroshkovaya Metallurgiya 8 (1992) 80-85.

[63] M. Sujata, S. Barghava, S. Sangal, ISIJ International 36 (1996) 255-262. 
[64] C. Li, N. Cheng, Z. Chen, Z. Xie, L. Hui, Materials 11 (2018) 636.

[65] L. Li, Effect of Magnetic Field on Crystallography and Microstructure of Ascast Al-based Binary Alloys, Ph.D. thesis, University of Paul Verlaine-Metz and Northeastern University, 2010.

[66] T. Clyne, M. Robert, Met. Technol. (1980) 177-185.

[67] Y. Fan, Precipitation Strengthening of Aluminum by Transition Metal Aluminides, Ph.D. thesis, Worcester Polytechnic Institute, 2012.

[68] F. Wang, D. Eskin, A. Khvan, K. Starodub, J. Lim, M. Burke, T. Connolley, J. Mi, Scripta Mater. 133 (2017) 75-78.

[69] J. Darby, D. Jugle, O. Kleppa, T. Metall. Soc. AIME 227 (1963) 179-185.

[70] R. Klein, I. Jacob, P. O’Hare, R. Goldberg, J. Chem. Thermodyn. 26 (1994) 599-608.

[71] A. Dinsdale, Calphad 15 (1991) 317-425.

[72] G. Ghosh, M. Asta, Acta Mater. 53 (2005) 3225-3252.

[73] H. Zhang, S. Wang, J. Mater. Res. 25 (2010) 1689-1694.

[74] P. Paradis, T. Ishikawa, S. Yoda, Adv. Space Res. 41 (2008) 2118-2125.

[75] P. Paradis, T. Ishikawa, T. Aoyama, S. Yoda, J. Chem. Thermodyn. 34 (2002) 1929-1942.

[76] S. Stankus, High Temp. 31 (1993) 684-689.

[77] R. Hixson, M. Winkler, M. Hodgdon, Phys. Rev. B 42 (1990) 6485-6491.

[78] A. Kirshenbaum, J. Cahill, T. ASM. 56 (1963) 281-286.

[79] W. Drotning, High Temp.-High Press. 13 (1981) 442-458. 